\title{
Design, Synthesis, and Post Vapor Treatment of Neutral Fulleropyrrolidine Electron-Collecting Interlayers for High-Efficiency Inverted Polymer Solar Cells
}

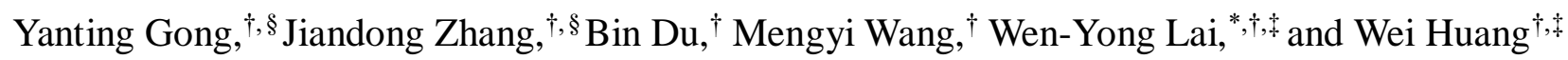

${ }^{\dagger}$ Key Laboratory for Organic Electronics and Information Displays \& Institute of Advanced Materials (IAM), Jiangsu National Synergetic Innovation Center for Advanced Materials (SICAM), Nanjing University of Posts \& Telecommunications, 9 Wenyuan Road, Nanjing 210023, China.

\$Shaanxi Institute of Flexible Electronics (SIFE), Northwestern Polytechnical University (NPU), 127 West Youyi Road, Xi'an 710072, Shaanxi, China.

*E-mail: iamwylai@njupt.edu.cn

${ }^{\S}$ Y.-T. Gong and J.-D. Zhang are co-first authors with equal contribution to this work. 


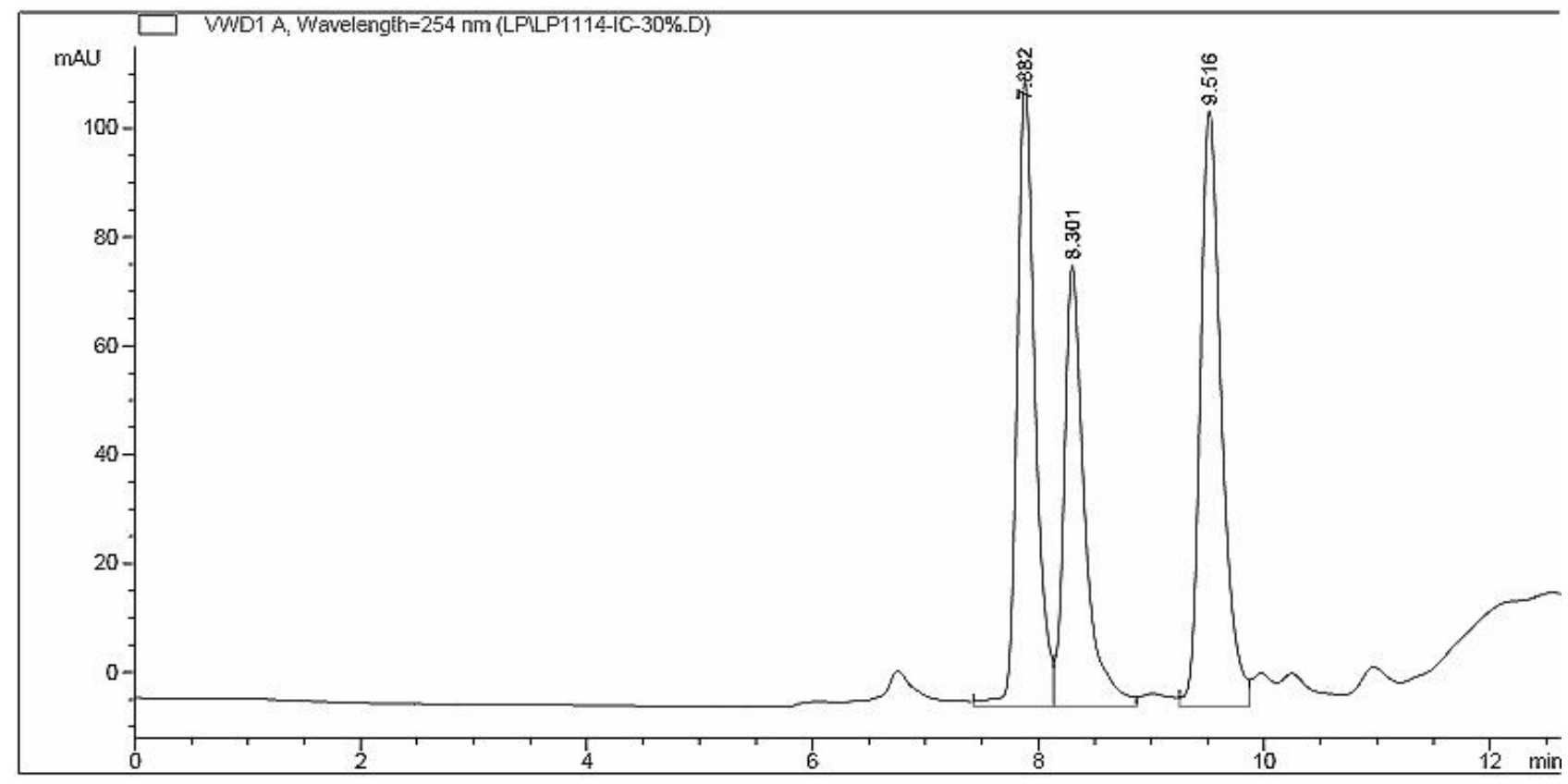

Figure S1. HPLC spectra for FBPBr

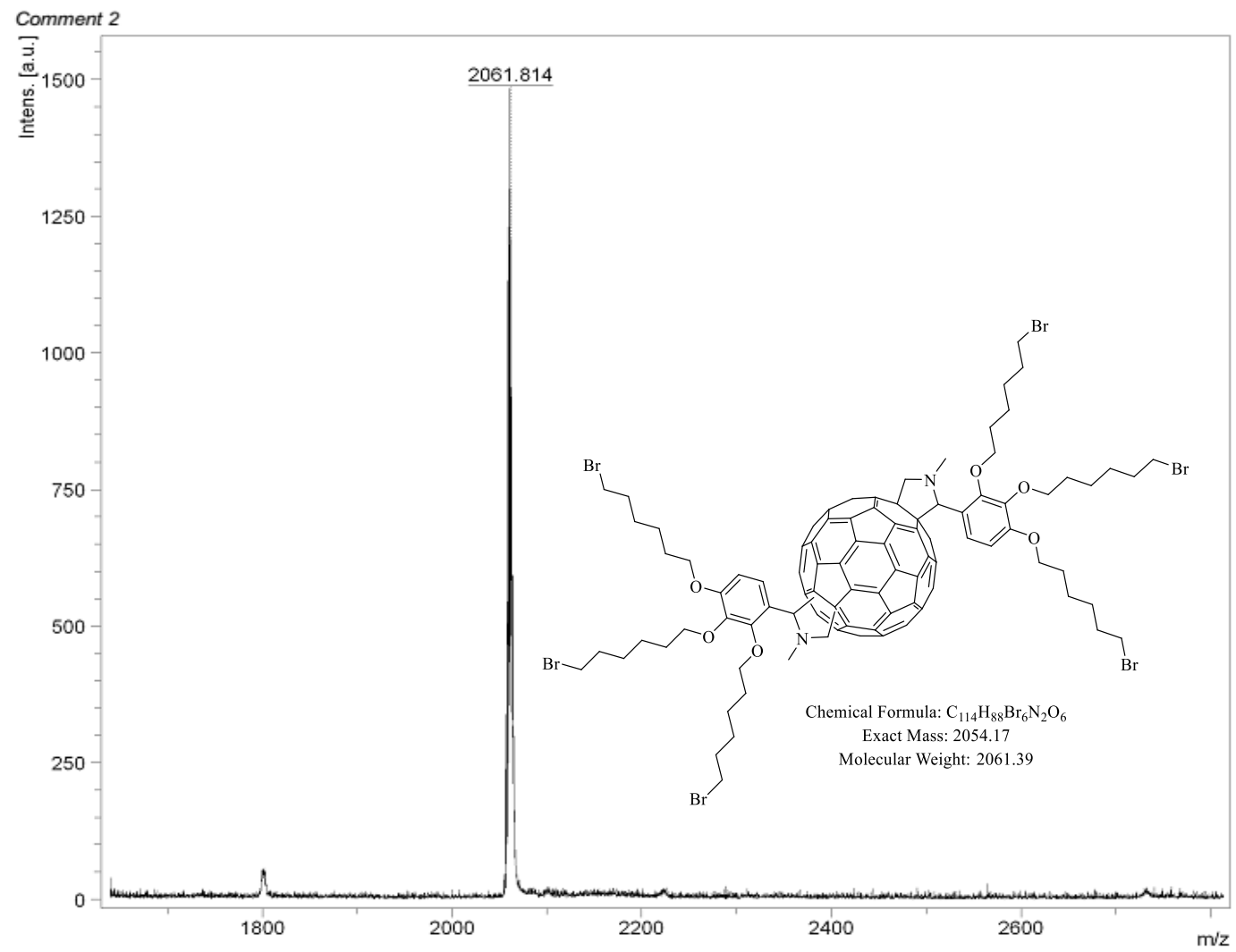

Figure S2. MALDI-TOF mass spectra for FBPBr 

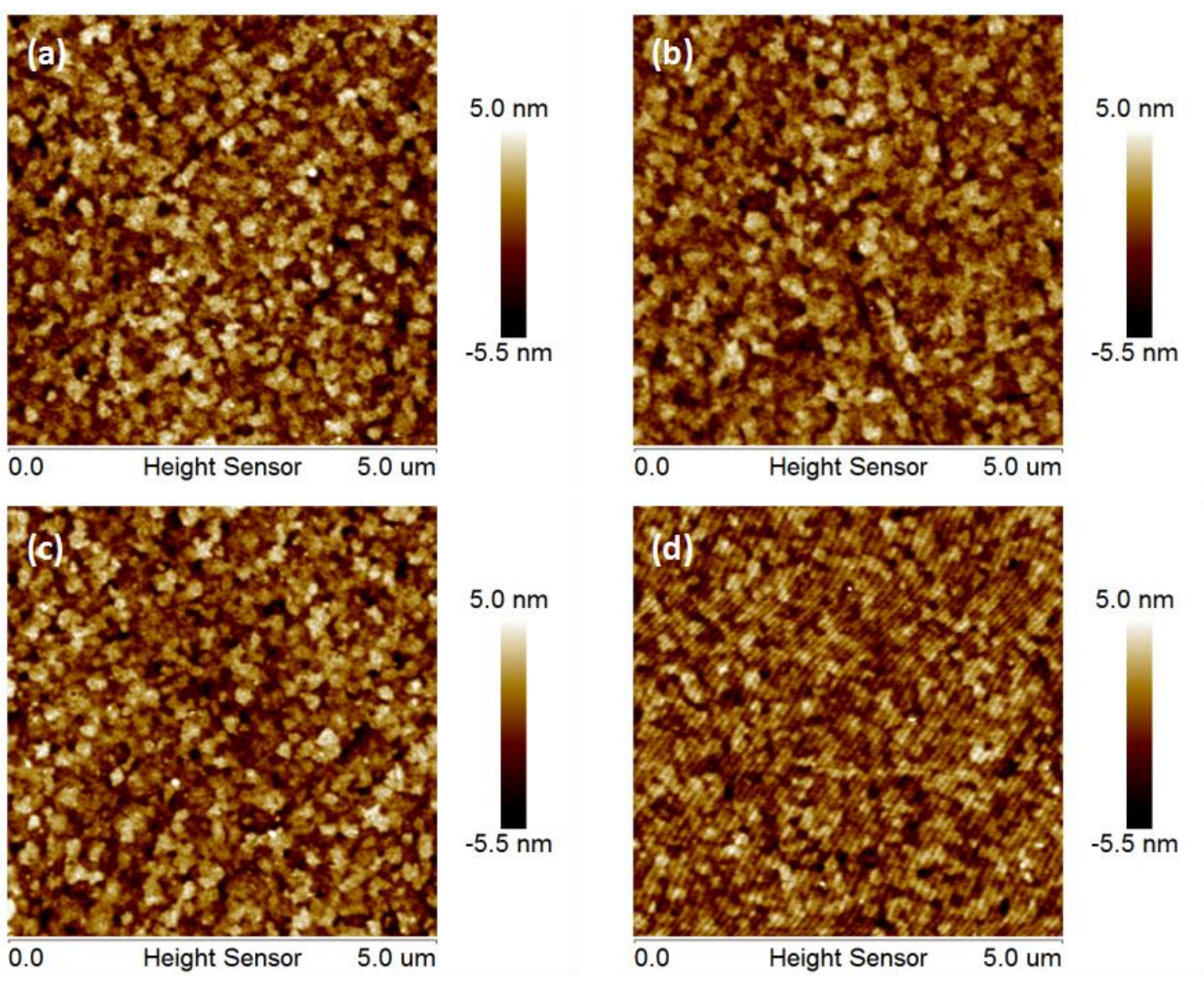

Figure S3. AFM surface topography of (a) FPNOH on ITO deal with thermal annealing (TA), (b)

FBPNOH on ITO deal with TA, (c) FPNOH on ITO deal with solvent annealing (SA) and (d) FBPNOH on ITO deal with SA. Scan size is $5 \mu \mathrm{m} \times 5 \mu \mathrm{m}$, and scan rate is $1 \mathrm{~Hz}$ for all images.

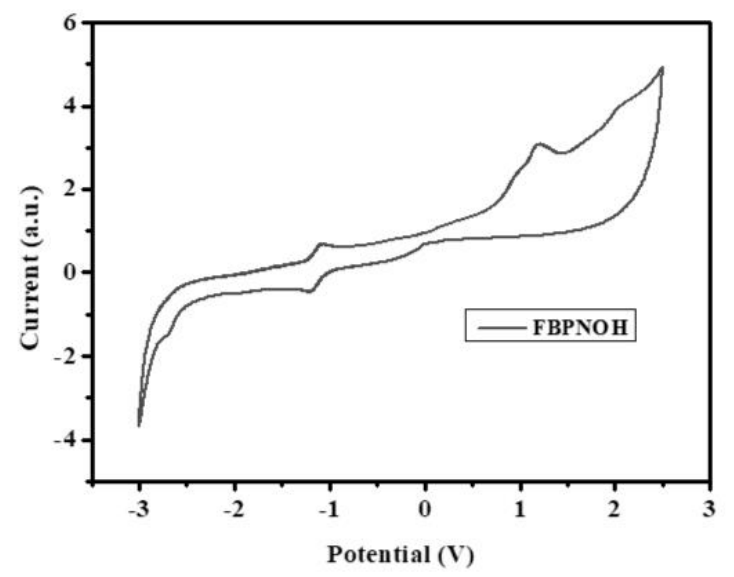

Figure S4. The CV for FBPNOH. 


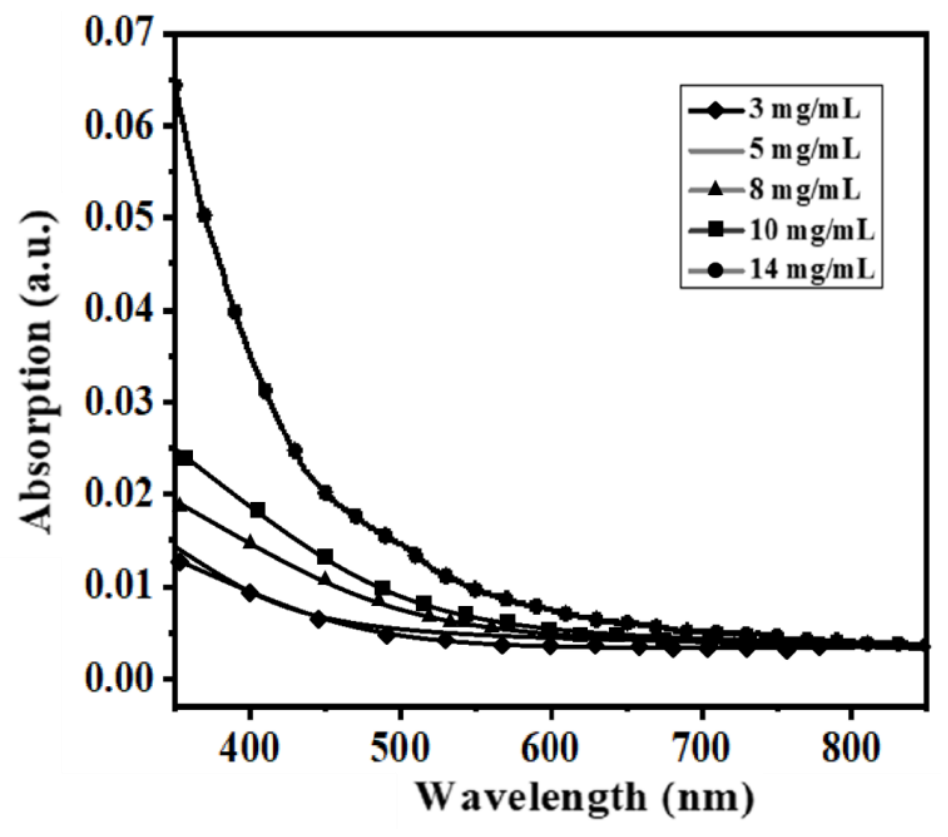

Figure S5. The absorption for FBPNOH films with various thickness.

Determination of the thickness: The average film thickness of FBPNOH films was calculated according to Beer' law:

$$
\varepsilon=\frac{A}{l}
$$

Where $\varepsilon$ is extinction coefficients; A is the absorption intensity and $l$ is the thickness. Pre-cleaned quartz slides were treated with $\mathrm{O}_{2}$ plasma prior to spin-casting. A thick film of FBPNOH was spin-coated from its hot DMF/HOAc $(97: 3)$ solution $\left(14 \mathrm{mg} / \mathrm{mL}, 100^{\circ} \mathrm{C}\right)$ at $1000 \mathrm{rpm}$, giving an average thickness of $32.2 \pm 1.2 \mathrm{~nm}$ (each absorption and thickness measurement was performed on three different positions to obtain an average value). UV-Vis absorption spectra were measured, followed by film thickness measurements using profilometry. Subsequently, $\varepsilon$ was determined at the wavelength of $350 \mathrm{~nm}$ using Beer's law. $\varepsilon$ was $20186 \mathrm{~cm}^{-1}$. Using $\varepsilon$ and the absorption intensity of thin films for device fabrication, the film thickness was adjusted by varying the concentrations of FBPNOH, which was calculated by Beer's law (e.g., $3 \mathrm{mg} / \mathrm{mL}$ yielded $6.4 \mathrm{~nm}$ films, $5 \mathrm{mg} / \mathrm{mL}$ yielded $7.4 \mathrm{~nm}$ films, $8 \mathrm{mg} / \mathrm{mL}$ yielded $9.9 \mathrm{~nm}$ films, and $10 \mathrm{mg} / \mathrm{mL}$ yielded $12.4 \mathrm{~nm}$ films). 


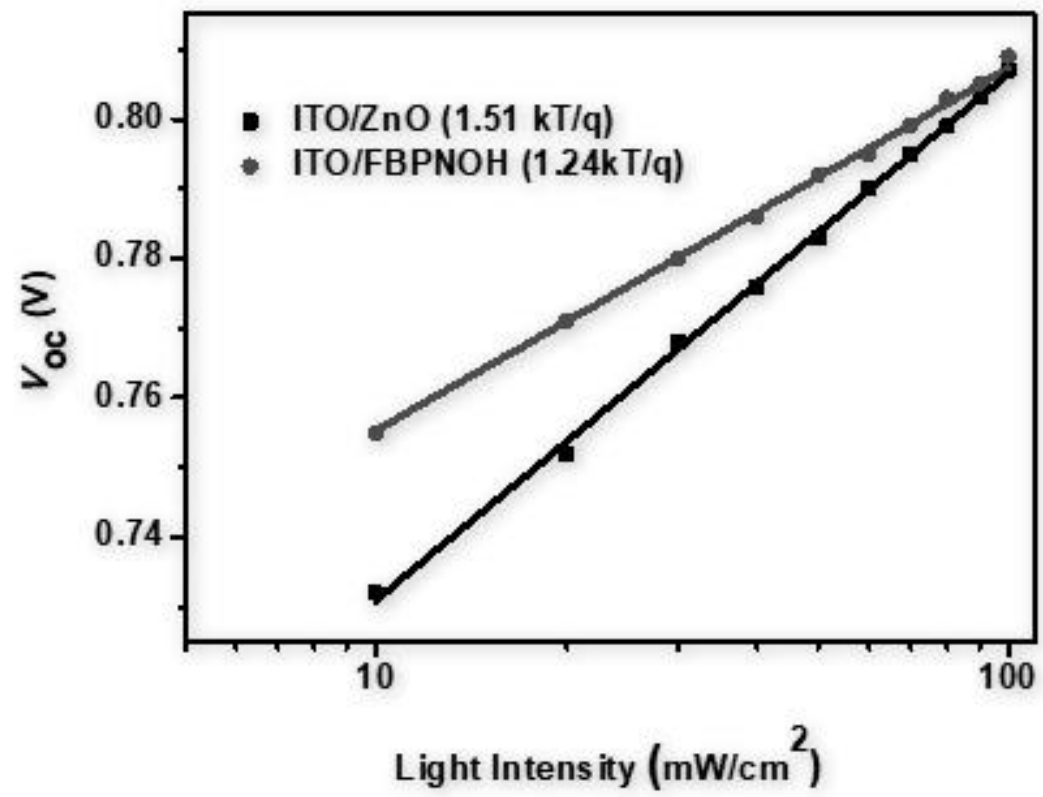

Figure S6. The light-intensity dependent Voc measurements without TA and SA treatments for ITO/ZnO and ITO/ PBFNOH based $i$-PSC devices.

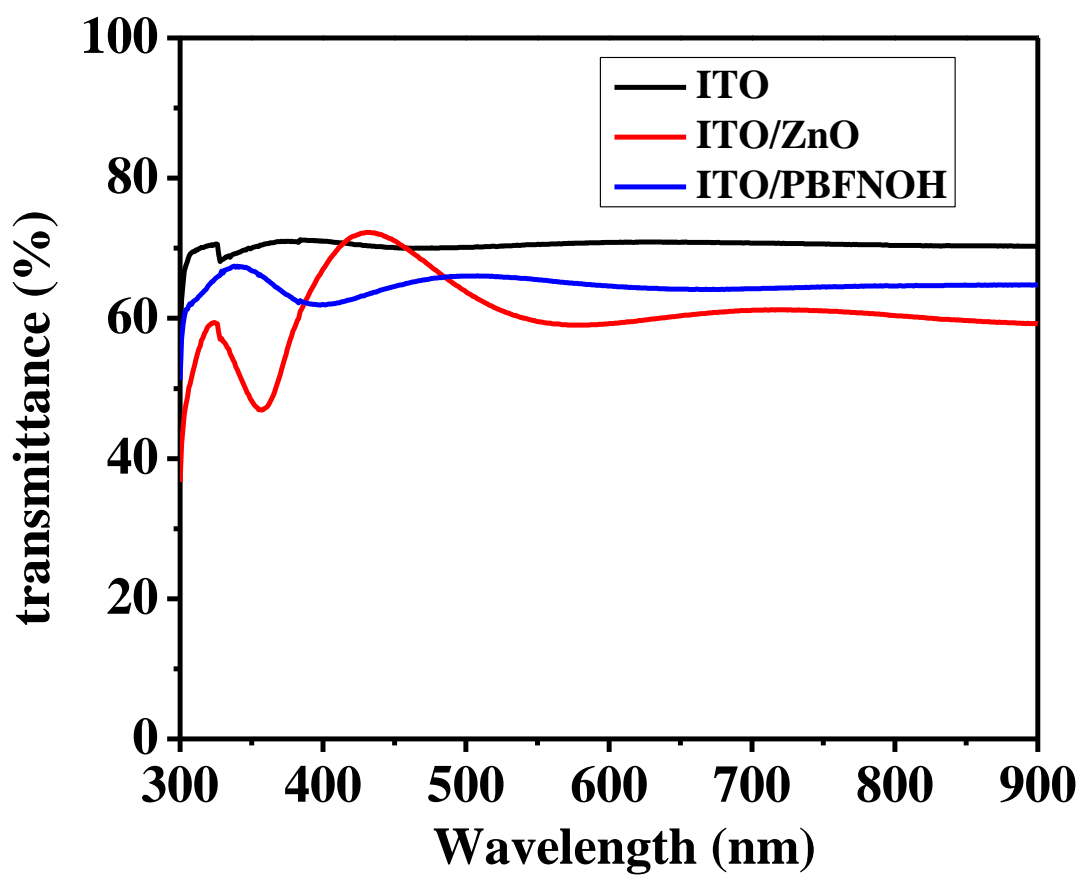

Figure S7. The transmittance spectra of ITO, ITO/ZnO, and ITO/PBFNOH films. 
Table S1. Device performance for the resulting $i$-PSCs based FBPNOH interlayer with various film thickness as compared with those of the $\mathrm{ZnO}$ reference device.

\begin{tabular}{ccccccc}
\hline Materials & $\begin{array}{c}V_{\mathrm{OC}} \\
(\mathrm{V})\end{array}$ & $\begin{array}{c}J_{\mathrm{SC}} \\
\left(\mathrm{mA} / \mathrm{cm}^{2}\right)\end{array}$ & $\begin{array}{c}\text { Interlayer } \\
\text { Thickness } \\
(\mathrm{nm})\end{array}$ & $\begin{array}{c}\text { FF } \\
(\%)\end{array}$ & $\begin{array}{c}\text { PCE } \\
(\%)\end{array}$ & $\begin{array}{c}\text { PCE } \\
(\%)\end{array}$ \\
\hline ZnO & $0.804 \pm 0.002$ & $16.08 \pm 0.3$ & 32.2 & $64.5 \pm 1.9$ & $8.20 \pm 0.10$ & 8.30 \\
FBPNOH & $0.747 \pm 0.003$ & $16.44 \pm 0.15$ & 6.4 & $67.0 \pm 1.4$ & $8.51 \pm 0.04$ & 8.55 \\
FBPNOH & $0.752 \pm 0.004$ & $16.57 \pm 0.22$ & 7.4 & $68.1 \pm 1.7$ & $8.67 \pm 0.18$ & 8.85 \\
FBPNOH & $0.754 \pm 0.009$ & $15.80 \pm 0.18$ & 9.9 & $64.1 \pm 0.8$ & $7.89 \pm 0.05$ & 7.94 \\
FBPNOH & $0.755 \pm 0.003$ & $15.80 \pm 0.13$ & 12.4 & $64.2 \pm 0.5$ & $7.53 \pm 0.29$ & 7.82 \\
\hline
\end{tabular}

